\title{
Acupuncture Point Localization Varies Among Acupuncturists
}

\author{
Petra I. Bäumler ${ }^{\mathrm{a}}$ Michael Simang ${ }^{\mathrm{a}, \mathrm{b}} \quad$ Sybille Kramer ${ }^{\mathrm{a}, \mathrm{c}} \quad$ Dominik Irnich $^{\mathrm{a}}$ \\ ${ }^{a}$ Multidisciplinary Pain Center, Department of Anesthesiology, \\ ${ }^{b}$ Institute for Medical Information Science, Biometry, and Epidemiology, \\ ${ }^{\circ}$ Interdisciplinary Center for Palliative Medicine, Department of Anesthesiology, University of Munich, Germany
}

\section{Keywords}

Acupuncture · Point localization · Bias · Survey ·

Bivariate distribution function

\section{Summary}

Background: Studies assessing the point-specific effect of acupuncture or the characteristics of acupuncture points (APs) tend to yield inconclusive results. In order to identify a possible confounding factor, we aimed to examine the variability in AP localization by means of a survey. Material and Methods: Attendees of the 14th ICMART (International Council of Medical Acupuncture and Related Techniques) congress as well as DÄGfA (German Medical Society of Acupuncture) lecturers and students were asked to locate and mark the APs LI 10 and TH 5 on a research assistant's arm. Identified points were transferred into a coordinate system, and the respective bivariate distribution function was calculated. Additionally, participants filled out a questionnaire about their acupuncture education and experience, the acupuncture style and point localization techniques used most frequently, and their estimation of the size of an AP. Results: The areas of the ellipses, theoretically containing $95 \%$ of AP localizations, varied between 44.49 and $5.18 \mathrm{~cm}^{2}$. The largest distance between 2 identified points was $8.45 \mathrm{~cm}$ for LI 10 and $5.3 \mathrm{~cm}$ for TH 5. Apart from being trained at the same school, no other factor could be identified that determined the variability in AP localization. Conclusion: Our results indicate that congruity of AP localization among experienced acupuncturists might be low. Although there are some limitations to our results, this possible bias should be taken into account when conducting acupuncture trials and interpreting results of previous acupuncture studies.

\author{
Schlüsselwörter \\ Akupunktur · Punktlokalisation - Systematischer Fehler . \\ Befragung · Bivariate Verteilungsfunktion
}

\section{Zusammenfassung}

Hintergrund: Studien zur punktspezifischen Wirkung der Akupunktur oder Charakterisierung von Akupunkturpunkten (AP) führen oft zu uneindeutigen Ergebnissen. Um eine hierzu mögliche Einflussgröße zu identifizieren, war Ziel unserer Studie, die Variabilität bei der AP-Lokalisation mittels einer Therapeutenbefragung zu untersuchen. Material und Methoden: Teilnehmer des 14. ICMART(International Council of Medical Acupuncture and Related Techniques)-Kongresses sowie Dozenten und Studenten der DÄGfA (Deutsche Ärztegesellschaft für Akupunktur) wurden gebeten, die Akupunkturpunkte LI 10 und TH 5 auf dem Arm einer Studienassistentin zu lokalisieren und zu markieren. Die identifizierten Punkte wurden in ein Koordinatensystem übertragen, und die entsprechende bivariate Verteilungsfunktion wurde berechnet. Zusätzlich wurden mittels eines Fragebogens die Akupunkturausbildung und -erfahrung der Teilnehmer, die von ihnen am häufigsten verwendeten Akupunkturstile und Punktlokalisationstechniken sowie ihre Einschätzung der Größe von AP abgefragt. Ergebnisse: Die Flächen der Ellipsen, die entsprechend der errechneten Verteilungsfunktionen 95\% der AP-Lokalisationen beinhalten, lagen zwischen 44,49 und $5,18 \mathrm{~cm}^{2}$. Die größte Distanz zwischen 2 Lokalisationen war $8,45 \mathrm{~cm}$ für LI 10 und $3,4 \mathrm{~cm}$ für TH 5. Neben einer Ausbildung am gleichen Institut wurde kein anderer Einflussfaktor identifiziert, von dem die Variabilität der AP-Lokalisation abhängt. Schlussfolgerung: Unsere Ergebnisse deuten darauf hin, dass eine geringe Übereinstimmung bei der AP-Lokalisation unter erfahrenen Akupunkteuren besteht. Trotz kleiner methodischer Mängel dieser Studie sollte dieses Ergebnis bei der Planung und Interpretation vorangegangener Akupunkturstudien Berücksichtigung finden.

\section{KARGER \\ Fax +497614520714 \\ Information@Karger.de}

www.karger.com
(C) 2012 S. Karger GmbH, Freiburg

1661-4119/12/0191-0031\$38.00/0

Accessible online at:

www.karger.com/fok
Petra I. Bäumler

Interdisziplinäre Schmerzambulanz, Abteilung für Anästhesiologie

Klinikum der Universität München

Pettenkoferstraße 8a, 80336 München, Germany

Tel. +49 8951603625 , Fax -7507

petra.baeumler@med.uni-muenchen.de 


\section{Introduction}

During acupuncture, specific points on the body are stimulated in order to remove blockages in the flow of qi and thereby restore and maintain health [1]. Thus, one of the important skills of an acupuncturist is to pick and localize acupuncture points (APs). This process is influenced by the acupuncturist's knowledge of the theoretical framework of acupuncture as well as the basis of his/her medical expertise in assessing a patient's condition [2]. The latest consensus on the localization of APs is represented by the WHO Standard on Acupuncture Point Locations in the Western Pacific Region [3]. Nonetheless, the point-specific effect of acupuncture is widely discussed. Various randomized controlled trials (RCTs) using needling at non-APs as a sham control, revealed a remarkable therapeutic effect of this control procedure $[4,5]$. Prominent examples are the German acupuncture trials GERAC and ART [6]. On the other hand, the AP-specific mode of action is recognized and supported by several studies; examples are PC 6 for controlling postanesthetic vomiting and nausea [7], or a acupuncture regimen involving LI 4 and LI 10 for the treatment of lateral epicondylitis $[8,9]$. Furthermore, brain imaging studies revealed that activation of certain brain areas is specifically associated with stimulation at APs [10-12].

Research on anatomical features and physiological characteristics of APs has not led to conclusive results and does not allow for an exact definition of such points [13]. Findings indicate a relationship among APs and myofascial trigger points $[14,15]$, connective tissue planes [16], and nerve-vessel bundles penetrating the superficial fasciae [17]; however, given the high occurrence of these structures, it remains unclear which of them are specific for APs. A significantly larger needle grasp [18] and larger blood supply into the microvascular beds [19] at APs when compared to other areas has been observed. Additionally, conflicting results also exist about APs being spots characterized by a high density of neural receptors $[20,21]$ or a distinct electrical skin resistance [22-24]. The fact that results of experimental as well as clinical research often appear multifarious and controversial might in part be due to technical challenges and shortcomings of the respective research projects [25]. A less often discussed but doubtlessly important confounding factor could be that it is difficult to control for exact localization and demarcation of the examined APs [23]. Should we not ensure that we are talking about identical sites before discussing their characteristics or therapeutic impact? Until now, few attempts have been made to assess the variability of AP localization [26, 27]. Thus, the aim of this study was to investigate by means of a survey whether acupuncturists are in agreement about the position of APs. Furthermore, we aimed to assess whether the duration of practical experience and acupuncture education, localization techniques, and country of acupuncture education might influence AP localization.

\section{Material and Methods}

\section{Participants}

Surveys were performed at the 14th Congress of the ICMART (International Council of Medical Acupuncture and Related Techniques) in Riga, Latvia, in May 2010, and at the DÄGfA (German Medical Society of Acupuncture, Deutsche Ärztegesellschaft für Akupunktur) central office in Munich, Germany, during an acupuncture seminar and a meeting of the DÄGfA scientific committee in June 2010. The ICMART congress was characterized by an international ambience with therapists attending from all over the world. All acupuncturists present on the second occasion had studied acupuncture at the DÄGfA or were part of the DÄGFA faculty. Participants took part voluntarily, were over 18 years of age, held an acupuncture degree, and had a good command of written and spoken English. Overall, we polled 30 acupuncturists at the ICMART congress and 12 at the DÄGfA central office.

\section{Design}

Participants were asked to localize the APs LI 10 and TH 5 on the left arm of a member of the study staff and to mark them with a makeup pen. According to the textbooks, LI 10 is located 2 cun distally from LI 11 on the connecting line of LI 5 and Li 11, and TH 5 is found 2 cun proximal to the dorsal wrist crease between the radius and the ulna [28, 29]. The person on whom the localization was performed was the same throughout the entire survey. Indicated locations for LI 10 and TH 5 were transferred immediately onto transparent plastic sheets by using 3 previously marked reference points. Markings on the skin were removed in order to provide identical conditions for every candidate. Additionally, every participating acupuncturist was given a short questionnaire about their practical acupuncture experience and education, the acupuncture styles and point localization techniques they used most frequently, and their estimation of the diameter of an AP.

\section{Drop Outs}

One acupuncturist only took part in the AP localization survey but did not return the questionnaire. He mentioned, however, that he was a US citizen and had studied acupuncture in his home country. Therefore, he was excluded from the respective analysis of the questionnaire besides the information about the country of his acupuncture education.

\section{Ethics}

The ethical committee of the University of Munich issued a declaration of no objection for the study proposal on May 7, 2010.

\section{Analysis}

The results of both surveys were analyzed separately. Points were collectively copied from the plastic sheets into a coordinate system by again using the 3 reference points. Resulting $\mathrm{x}$ - and $\mathrm{y}$-values of the coordinates were normally distributed according to the Kolmogorov-Smirnow test. For the localization of LI 10 and TW 5 by both groups, the respective bivariate distribution functions were defined by calculating the distribution parameters from the empirical data. Thereby, ellipses which theoretically contain $95 \%$ of all points defined by the respective distributions could be circumscribed. In a next step, we assessed in a descriptive graphical manner whether parameters surveyed with the questionnaire did have an influence on AP localization. Due to the small case number, a meaningful statistical comparison of subgroups was not possible.

\section{Results}

\section{Participant Characteristics: ICMART Congress}

A total of 18 (60\%) female and $12(40 \%)$ male acupuncturists who had received acupuncture education (additional semi- 
Table 1. International acupuncture scene at the ICMART congress: the polled participants $(n=30)$ had received acupuncture education in 19 different countries with China being the most frequented

\begin{tabular}{lc}
\hline Country of acupuncture education & ICMART participants, $\mathrm{n}$ \\
\hline Austria & 1 \\
Brazil & 1 \\
China & 10 \\
Denmark & 1 \\
France & 1 \\
Germany & 6 \\
Hungary & 1 \\
Israel & 1 \\
Japan & 3 \\
Latvia & 3 \\
Netherlands & 4 \\
Norway & 3 \\
Russia & 3 \\
Singapore & 1 \\
Switzerland & 1 \\
Czech Republic & 1 \\
Ukraine & 1 \\
USA & 5 \\
Vietnam & 1 \\
\hline
\end{tabular}

Table 2. Duration of acupuncture education and practical experience: $86.2 \%$ of the ICMART group and $50 \%$ of the DÄGfA group had received more than $300 \mathrm{~h}$ of acupuncture education, and $68.9 \%$ of the ICMART group and $50 \%$ of the DÄGfA group had practiced acupuncture for more than 10 years

\begin{tabular}{lll}
\hline & \multicolumn{2}{l}{ Group, $\mathrm{n}(\%)$} \\
\cline { 2 - 3 } & $\begin{array}{l}\text { ICMART } \\
(\mathrm{n}=29)\end{array}$ & $\begin{array}{l}\text { DÄGfA } \\
(\mathrm{n}=12)\end{array}$ \\
\hline $\begin{array}{l}\text { Duration of acupuncture education, h } \\
\quad<100\end{array}$ & - & $1(8.3)$ \\
$100-300$ & $4(13.8)$ & $5(41.7)$ \\
$300-500$ & $9(31.0)$ & $2(16.7)$ \\
$>500$ & $16(55.2)$ & $4(33.3)$ \\
Practical acupuncture experience, years & & \\
$<1$ & $1(3.4)$ & $1(8.3)$ \\
$<3$ & $2(6.9)$ & $2(16.7)$ \\
$<5$ & $2(6.9)$ & $2(16.7)$ \\
$<10$ & $4(13.8)$ & $1(8.3)$ \\
$<20$ & $6(20.7)$ & $3(25)$ \\
$<30$ & $11(37.9)$ & $3(25)$ \\
$>30$ & $3(10.3)$ & - \\
\hline
\end{tabular}

nars, courses, and internships included) in 19 different countries participated voluntarily in the survey at the ICMART congress (table 1). The country mostly frequented for acupuncture training was China: $10(33.3 \%)$ participants had received at least part of their acupuncture education there, while $3(10 \%)$ were Chinese and had completed their basic training in China. 25 (86.2\%) therapists had completed more
Table 3. Acupuncture style and point localization technique most frequently used (multiple answers permitted): most acupuncturists applied the concept of Traditional Chinese Medicine (TCM) or Western Style Acupuncture, and $51.7 \%$ practiced more than 1 acupuncture style; most participants used the cun for body acupuncture and the Very Point Technique ${ }^{\circledR}$ for microsystem acupuncture

\begin{tabular}{|c|c|c|}
\hline & \multicolumn{2}{|c|}{ Group, n (\%) } \\
\hline & $\begin{array}{l}\text { ICMART } \\
(\mathrm{n}=29)\end{array}$ & $\begin{array}{l}\text { DÄGfA } \\
(\mathrm{n}=12)\end{array}$ \\
\hline \multicolumn{3}{|c|}{ Acupuncture style most commonly used } \\
\hline TCM & $26(89.7)$ & $8(66.7)$ \\
\hline Japanese & $7(24.1)$ & $1(8.3)$ \\
\hline Western & $14(48.3)$ & $7(58.3)$ \\
\hline Korean & $1(3.4)$ & $1(8.3)$ \\
\hline \multicolumn{3}{|c|}{$\begin{array}{l}\text { Acupuncture point localization technique } \\
\text { during body acupuncture }\end{array}$} \\
\hline Cun & $22(75.9)$ & $10(83.3)$ \\
\hline Skin resistance & $3(10.3)$ & $2(16.7)$ \\
\hline Very point technique $^{\circledR}$ & $5(17.2)$ & $7(58.3)$ \\
\hline Intuition & $11(37.9)$ & $5(41.7)$ \\
\hline $\mathrm{RAC}$ & $4(13.8)$ & - \\
\hline Palpation & $14(48.3)$ & $1(8.3)$ \\
\hline Structure, knowledge & - & - \\
\hline \multicolumn{3}{|c|}{$\begin{array}{l}\text { Acupuncture point localization technique } \\
\text { during microsystem acupuncture }\end{array}$} \\
\hline Cun & $7(26.9)$ & $2(16.7)$ \\
\hline Skin resistance & $4(15.4)$ & $1(8.3)$ \\
\hline Very point technique $^{\circledR}$ & $11(42.3)$ & $11(91.7)$ \\
\hline Intuition & $8(30.8)$ & $1(8.3)$ \\
\hline $\mathrm{RAC}$ & $2(7.7)$ & $1(8.3)$ \\
\hline Palpation & $1(3.8)$ & - \\
\hline Structure, knowledge & $4(15.4)$ & - \\
\hline
\end{tabular}

than $300 \mathrm{~h}$ of acupuncture education, and $4(13.8 \%)$ had completed 100-300 h; none of the participants had received less than $100 \mathrm{~h}$ of training (table 2$) .20(69.0 \%)$ persons stated that they had been practicing acupuncture for more than 10 years, and $9(31.0 \%)$ less than 10 years; 1 participant had less than 1 year of practical acupuncture experience (table 2). About half of the acupuncturists $(15(51.7 \%))$ reported to practice more than 1 acupuncture style. Most of the acupuncturists (26 $(89.7 \%))$ indicated that they applied acupuncture according to Traditional Chinese Medicine (TCM); this was followed by Western Style acupuncture which 14 (48.3\%) participants indicated to use (table 3 ). With regard to the technique used for point localization, most acupuncturists $(22$ (75.9\%)) answered that they would use the individualized gauge, the cun, during body acupuncture. The second most common entry for that question was intuition, indicated by 11 (37.9\%) participants. $26(89.7 \%)$ therapists stated that they also performed microsystem acupuncture. Here, the method mostly applied for point localization was the Very Point Technique ${ }^{\circledR}$ according to Gleditsch, which was used by $11(42.3 \%)$ participants (table 3). 
ICMART: LI 10

A

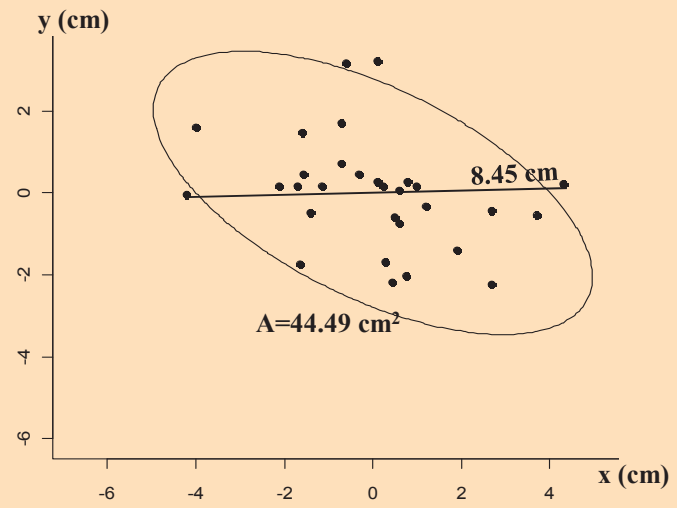

Fig. 1. Acupuncture point localization. A Points for LI 10 and TH 5 indicated by both groups were transferred into a coordinate system. Lines display the most distant markings. B The ellipses and corresponding areas that, according to the bivariate distribution function, contain $95 \%$ of point localizations were calculated (95\% quantiles).

B

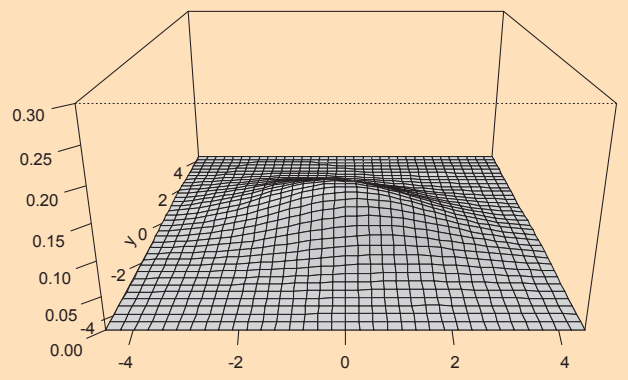

DÄGfA: LI 10
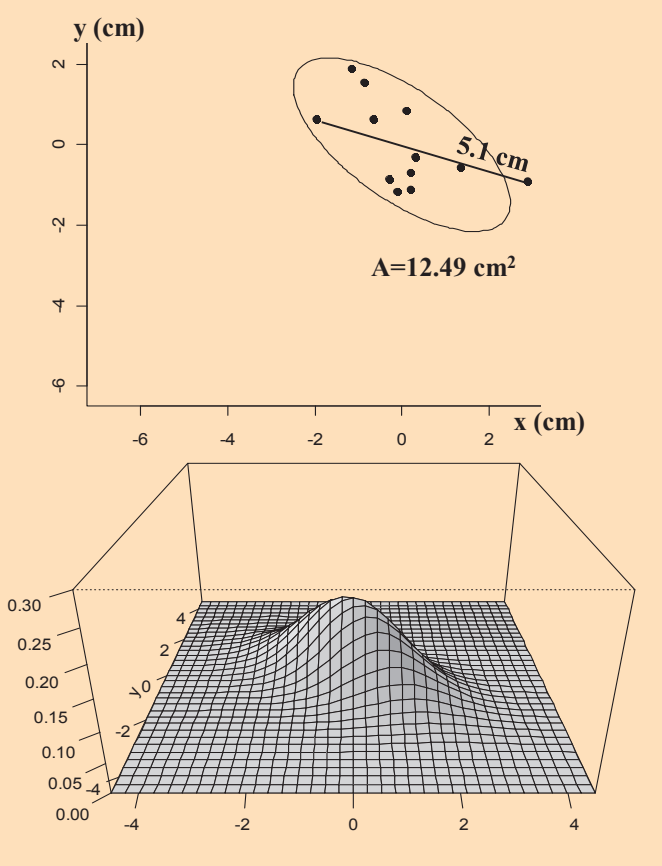

Fig. 2. Variability of acupuncture point localization among different subgroups identified. Locations for LI 10 determined by the ICMART group are given as an example. Filled dots $(\bullet)$ represent point locations indicated by acupuncturists who $\mathbf{A}$ have received part of their acupuncture education in China, B completed more than $500 \mathrm{~h}$ of acupuncture training, $\mathbf{C}$ have more than 20 year of practical experience,

$\mathbf{D}$ are men, and $\mathbf{E}$ usually use the cun for point localization. Empty dots $(\bigcirc)$ display markings of acupuncturists with the respective opposite characteristics. Grey dots $(\bullet)$ represent the points indicated by a participant who failed to
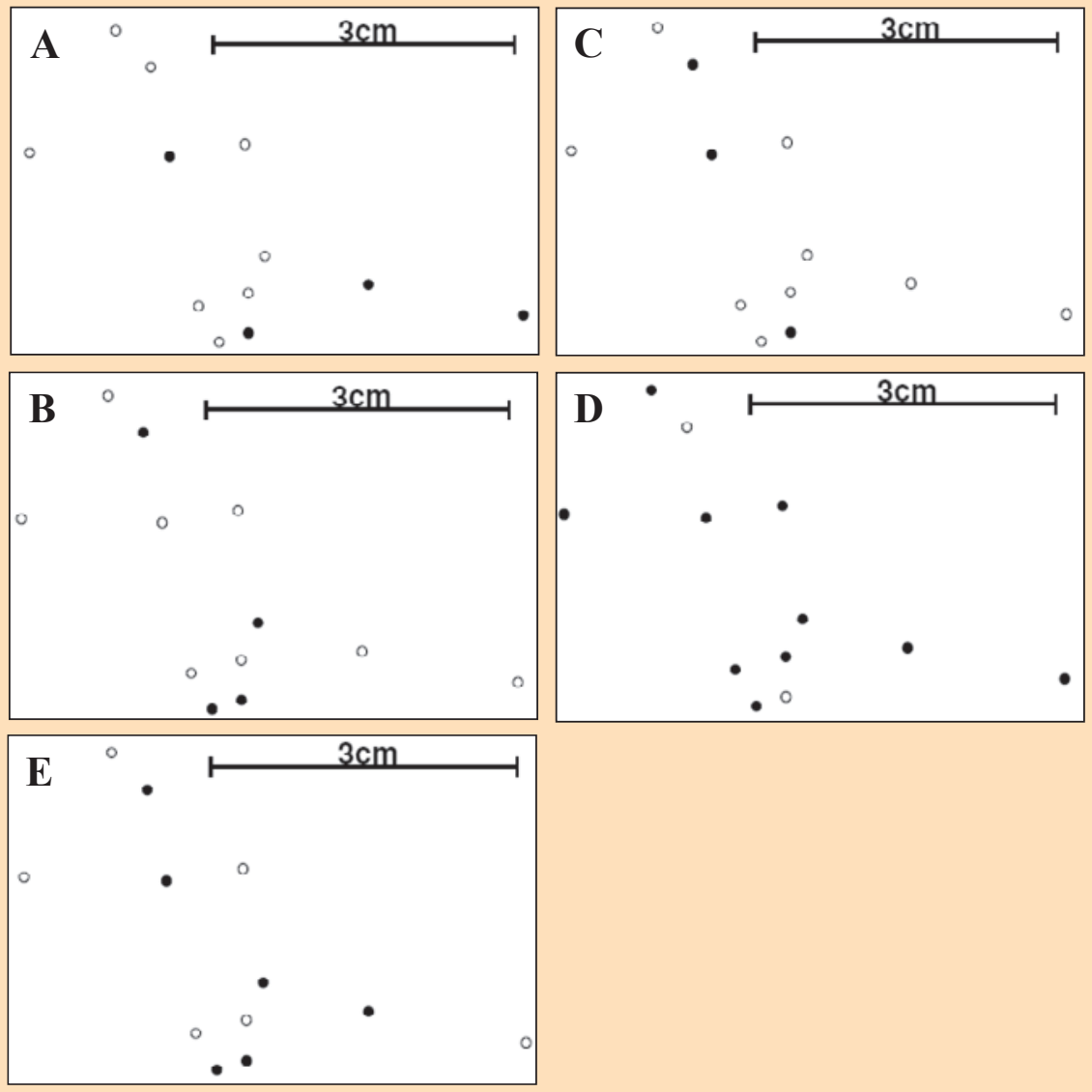
return the questionnaire. 


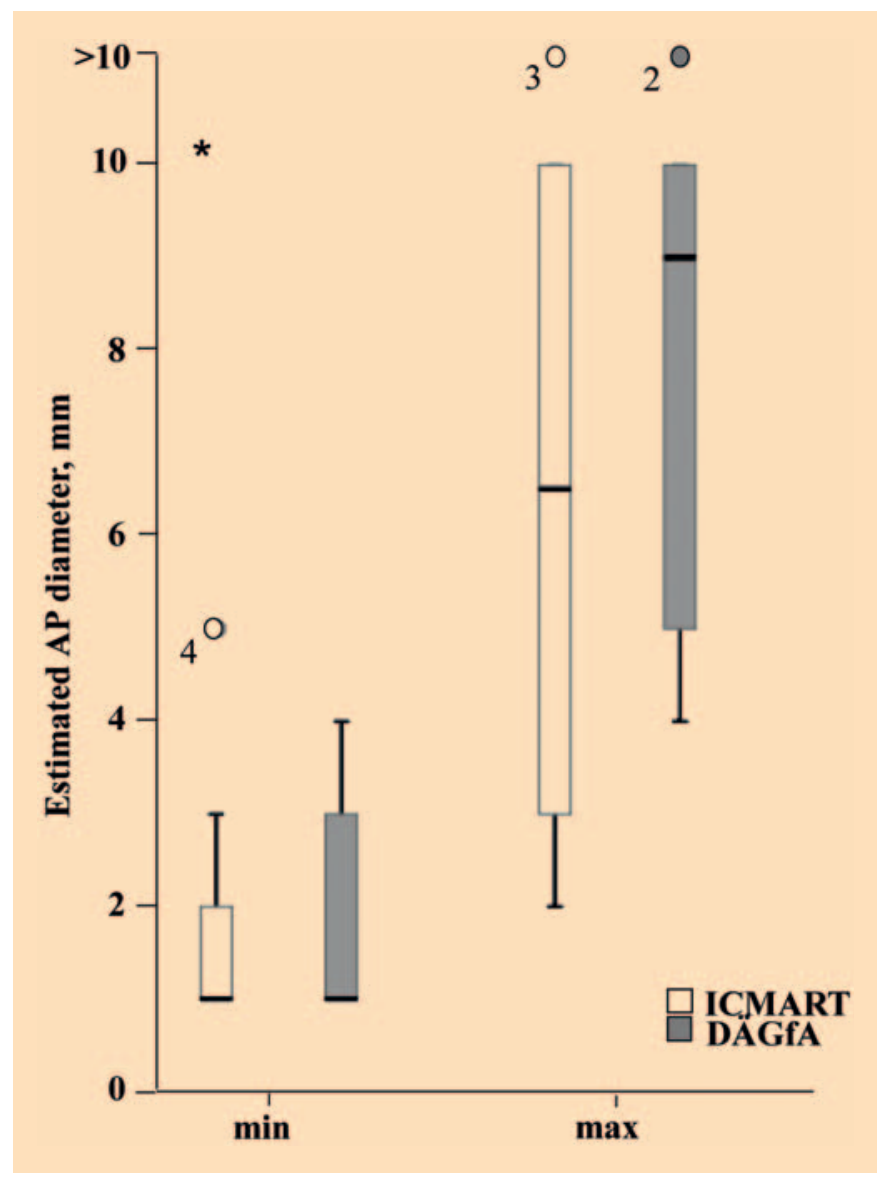

Fig. 3. Acupuncture point size estimation. Estimations of the minimum and maximum point diameter varied between acupuncturists of both groups. 3 participants of the ICMART and 2 of the DÄGfA group pointed out that the scale given in the questionnaire which covered a range of $0-10 \mathrm{~mm}$ was insufficient, and indicated the maximum diameter of acupuncture points to be larger than $10 \mathrm{~mm}$. 4 therapists polled at the ICMART congress were opposed to such an estimation.

\section{Participant Characteristics: $D \ddot{A} G f A$}

At the DÄGfA central office, 6 (50\%) women and 6 (50\%) men were included in the survey. All had completed basic acupuncture training at the DÄGfA and have been continuing their acupuncture education in subsequent seminars and courses. Half of the participants $(n=6)$ stated to have received more than $300 \mathrm{~h}$ and the other half less than $300 \mathrm{~h}$ of acupuncture education, while $1(8.3 \%)$ therapist indicated to have completed less than $100 \mathrm{~h}$ of acupuncture training (table 2). $4(33.3 \%)$ participants reported to have received additional acupuncture training in China. Also, half the acupuncturists had more than 10 years and the other half less than 10 years of practical acupuncture experience, with 1 participant having practiced acupuncture for less than 1 year (table 2). 4 (33.3\%) therapists stated to frequently use more than 1 acupuncture style, and most indicated to apply acupuncture according to TCM $(8(66.7 \%))$ and Western Style Acupuncture (7 $(58.3 \%))$ (table 3$)$. With regard to AP localization techniques, during body acupuncture, most participants (10 (83.3\%)) stated to use the cun; however, $8(66.7 \%)$ reported to use more than 1 technique to identify the APs. All acupuncturists of the DÄGfA stated that they also performed microsystem acupuncture for which the Very Point Technique ${ }^{\circledR}$ is the most frequently used (11 $(91.7 \%))$; only $4(33.3 \%)$ participants answered that they would use more than 1 localization technique (table 3 ).

\section{Point Localization}

As an example for the resulting distribution of located points, the marked points for LI 10 are displayed in figure $1 \mathrm{~A}$. The largest distance between 2 APs indicated by the acupuncturists surveyed at the ICMART congress was $8.45 \mathrm{~cm}$ for LI 10 and $5.3 \mathrm{~cm}$ for TH 5. Within the points marked by the DÄGfA acupuncturists, the largest distance was $5.1 \mathrm{~cm}$ for LI 10 and $3.4 \mathrm{~cm}$ for TH 5. Figure $1 \mathrm{~B}$ shows the bivariate distribution function for the acupuncture point LI 10 as indicated by the 2 groups. The areas of the ellipses containing $95 \%$ of the marked points are $44.49 \mathrm{~cm}^{2}$ for LI 10 and $10.98 \mathrm{~cm}^{2}$ for TH 5 in the ICMART and $12.49 \mathrm{~cm}^{2}$ for LI 10 and $5.18 \mathrm{~cm}^{2}$ for TH 5 in the DÄGfA group. The scatter range of points identified by the DÄGfA group is smaller than that of the points identified by the ICMART group (30.9\% for LI 10 and $42.2 \%$ for TH 5). The points indicated in both surveys were no more consistent when marked by therapists who had received at least some of their acupuncture education in China (fig. 2A), are very well educated in terms of having received more than $500 \mathrm{~h}$ of training (fig. 2B), or are extensively experienced in terms of more than 20 years of acupuncture practice (fig. 2C). Furthermore, AP localization was not more consistent if indicated by men or women (fig. 2D) or when therapists used the cun for point identification (fig. 2E).

\section{Point Size Estimation and Comments}

AP size estimation varied broadly between participants as displayed in figure 3. The minimum diameter of an AP was estimated to be $1 \mathrm{~mm}$ by about half the interviewees of both surveys $(14(48.3 \%)$ of the ICMART and $7(58.3 \%)$ of the DÄGfA group). For the maximum AP size, a diameter of $1 \mathrm{~cm}$ or larger was assumed most frequently $(10$ (34.5\%) of the ICMART and 7 (58.3) of the DÄGfA group). Four participants at the ICMART congress were opposed to estimating the minimum or maximum diameter of an AP. They commented consistently that in their opinion such an estimation was difficult to make. They gave reasons that were also pointed out by other participants at the ICMART. 5 (17.24\%) acupuncturists commented that APs were fields or areas instead of points. Another 5 stated that the size of an AP depends on the location of the particular point as well as on the age and condition of the patient. This thesis was also supported by $1(8.3 \%)$ DÄGfA acupuncturist who was, however, the only one to leave a comment on the questionnaire. This participant also purported that '....an AP is a point that works!'. 


\section{Discussion}

In both surveys, identified AP locations varied between participating acupuncturists. Areas of the ellipses, theoretically containing $95 \%$ of AP locations, ranged from 44.49 to $5.18 \mathrm{~cm}^{2}$ (fig. 1A). Especially when taking into account the perimeter of the assistant's underarm $(24 \mathrm{~cm})$ and wrist $(16 \mathrm{~cm})$, the large variance between marked APs becomes even more apparent. No subgroup indicated APs with remarkable congruity (fig. 2). Hence, on the basis of our results it cannot be conjectured that men locate APs differently from women (fig. 2D), or that more experienced and extensively trained acupuncturists are more precise than beginners (figs. 2B, C), although the majority of acupuncturists polled in this survey can be considered experienced based on their extensive acupuncture education and long years of practice (table 2). Points indicated by therapists who had received some part of their acupuncture education in China (fig. 2A) also failed to concur, which indicates the absence of country-specific factors influencing point localization. However, the fact that acupuncture according to TCM is applied by a large percentage of both survey groups (table 3 ) reflects its substantial role in the acupuncture community on a global scale. Consequently, the cun is the most frequently used technique to localize APs. Albeit, acupuncturists used to applying the cun as localization technique (fig. 2E) did not yield more congruent results.

Our findings suggest an individual component playing a role in AP localization and accounting for the respectively large spread of marked points. Indeed, half of the participants suggested a maximum point size of $1 \mathrm{~cm}$ or larger, and 4 refused to estimate such a point size at all. This is in line with the frequent comment about APs being fields or that their size depended on various factors. Such statements might indicate that the therapists' understanding of APs contrasts the idea of strictly defined spots and favors an in part intuitive approach to point localization. In fact, about $40 \%$ of the acupuncturists polled on both occasions reported to frequently use their intuition to identify points during body acupuncture (table 3). However, as mentioned before, points did also not coincide more when identified by those using the cun which represents an exactly defined gauge. In contrast, the variance of the AP locations indicated by the DÄGfA group was smaller than that of the points identified by the ICMART group. This trend suggests a higher congruity in point localization among acupuncturists being trained at the same institution than among a heterogeneous group of therapists.

One might argue that the simple design of this survey might exhibit limitations. First, the method of transferring marks from an arm as a 3-dimensional object to a 2-dimensional plastic sheet, albeit with maximum diligence, might lead to certain impreciseness. However, this fact is unlikely to account for such great variance as observed. Additionally, conditions for participants were not ideal, given the lively atmosphere at both events. Moreover, colleagues watching them curiously during the experiment might have distracted some acupuncturists. It also may be questioned whether all acupuncturist actually agreed on the theoretical position of LI 10 and TH 5, since we only documented the marked points but not how they were localized. During personal communication with participants, it was also discussed that text books and acupuncture schools might differ at least slightly in the definition of AP locations. Another subject of debate might be the fact that preferred needling angles were not reported. Assuming that APs are located underneath the skin, different needling angels naturally would result in different spots for insertion although the needle tip would penetrate the same target within the tissue. Especially when points are located in a particularly curved area like LI 10 (over the musculus extensor carpi radialis longus), differently assumed needling angles might have yielded the relatively large spread of marked APs. This might explain in part why in both groups the variance between LI 10 localizations was much larger than between TH 5 localizations. In future trials, a possible improvement might be to clarify whether participants are supposed to indicate points on the skin which are closest to the deeper structure aimed at or the spots where they would penetrate the skin with the needle. It also might be of interest for the acupuncture community to find a consensus regarding the depth of APs. It is unlikely that the large variance of AP localizations identified in this survey is solely due the points discussed above. However, it is important to not interpret our results with regard to the quality of acupuncture education or experience of the therapists polled. From our results, it cannot be conjectured which factors account for the poor congruity in AP localization. Furthermore, it cannot be concluded which locations for LI 10 and TH 5 were correct. However, the fact that APs indicated by experienced acupuncturists differed by up to $8.45 \mathrm{~cm}$, needs to be taken into account when interpreting and performing acupuncture trials, especially when evaluating the effectiveness of acupuncture per se in RCTs using needling at non-APs as a control intervention. In a number of acupuncture RCTs, non-APs are defined by a certain distance to classical APs, which can be as small as 1 cun (about $1.5 \mathrm{~cm}$ ) [30]. Assuming that our preliminary results will be confirmed by larger and more sophisticated experiments, it needs to be questioned whether verum and control point needling differed significantly in such trials. We propose to consider this possible source of bias systematically when drawing conclusions from RCTs and meta-analyses, because misinterpretation might result in clinical guidelines that preclude the recommendation of a valuable treatment. A comparison between an acupuncture regimen and conventional care might be more appropriate when assessing the effectiveness of this treatment.

Unquestionably, further research is needed to elucidate the impact and perhaps the definition of the point-specific effects 
of acupuncture. Although there are some limitations to our findings, they should been taken into account when designing new and interpreting previous acupuncture trials. Acupuncturists should control for incongruity in point localization, and techniques used for AP localization should be reported with great accuracy.

\section{Acknowledgement}

We thank Dr. med. Johannes Fleckenstein for his helpful advice and discussion.

\section{Disclosure Statement}

The authors declare that they have no conflict of interests.

\section{References}

1 NCCAM: Acupuncture: An Introduction. NCCAM publication no. D404, 2007/2009; available from nccam.nih.gov/health/acupuncture/introduction. htm.

2 Qiu ML: Chinese Acupuncture and Moxibustion, Edinburgh, Churchill Livingstone, 1993.

3 World Health Organization: WHO Standard on Acupuncture Point Locations in the Western Pacific Region. WHO, 2008; available from $w w w$. wpro.who.int/publications/PUB_9789290613831.htm.

4 Campbell A: Point specificity of acupuncture in the light of recent clinical and imaging studies. Acupunct Med 2006;3:118-122.

5 Langevin HM, Wayne PM, Macpherson H, Schnyer R, Milley RM, Napadow V, Lao L, Park J, Harris RE, Cohen M, Sherman KJ, Haramati A, Hammerschlag R: Paradoxes in acupuncture research: strategies for moving forward. Evid Based Complement Alternat Med 2011;2011:180805.

6 Cummings M: Modellvorhaben Akupunktur - a summary of the ART, ARC and GERAC trials Acupunct Med 2009;1:26-30.

7 Lee A, Fan LT: Stimulation of the wrist acupuncture point $\mathrm{P} 6$ for preventing postoperative nausea and vomiting. Cochrane Database Syst Rev 2009;2 CD003281.

8 Fink M, Wolkenstein E, Luennemann M, Gutenbrunner C, Gehrke A, Karst M: Chronic epicondylitis: effects of real and sham acupuncture treatment: a randomised controlled patient- and examinerblinded long-term trial. Forsch Komplementmed 2002;4:210-215.

9 Irnich D, Kar H, Lang PM, Schreiber MA, Krauss M, Kröling P: Controlled trial on point specificity of acupuncture in the treatment of lateral epicondylitis (tennis elbow). Phys Med Rehab Kuror 2003;13:215-219.

10 Dhond RP, Kettner N, Napadow V: Neuroimaging acupuncture effects in the human brain. J Altern Complement Med 2007;6:603-616.
11 Fang JL, Krings T, Weidemann J, Meister IG, Thron A: Functional MRI in healthy subjects during acupuncture: different effects of needle rotation in real and false acupoints. Neuroradiology 2004;5:359-362.

12 Harris RE, Zubieta JK, Scott DJ, Napadow V, Gracely RH, Clauw DJ: Traditional Chinese acupuncture and placebo (sham) acupuncture are differentiated by their effects on mu-opioid receptors (MORs). Neuroimage 2009;3:1077-1085.

13 Pomeranz B: Acupuncture points - do they really exist?; in Stux G, Hammerschlag R (eds): Clinical Acupuncture - Scientific Basis. Heidelberg, Springer-Verlag, 2001, pp. 12-17.

14 Melzack R, Stillwell DM, Fox EJ: Trigger points and acupuncture points for pain: correlations and implications. Pain 1977;1:3-23.

15 Dorsher PT, Fleckenstein J: Trigger points and classical acupuncture points: part 1: qualitative and quantitative anatomic correspondences. Dtsch Zeitschr Akupunkt 2008;3:15-24.

16 Langevin HM, Yandow JA: Relationship of acupuncture points and meridians to connective tissue planes. Anat Rec 2002;6:257-265.

17 Heine H: Anatomical structure of acupoints. J Tradit Chin Med 1988;3:207-212.

18 Langevin HM, Churchill DL, Fox JR, Badger GJ, Garra BS, Krag MH: Biomechanical response to acupuncture needling in humans. J Appl Physiol 2001;6:2471-2478.

19 Hsiu H, Huang SM, Chao PT, Jan MY, Hsu TL, Wang WK, Wang YY: Microcirculatory characteristics of acupuncture points obtained by laser Doppler flowmetry. Physiol Meas 2007;10:N77-86.

20 Dung HC: Anatomical features contributing to the formation of acupuncture points. Am J Acupunct 1984;4:139-143.

21 Wick F, Wick N, Wick MC: Morphological analysis of human acupuncture points through immunohistochemistry. Am J Phys Med Rehabil 2007;1:7-11.
22 Ahn AC, Colbert AP, Anderson BJ, Martinsen OG, Hammerschlag R, Cina S, Wayne PM, Langevin HM: Electrical properties of acupuncture points and meridians: a systematic review. Bioelectromagnetics 2008;4:245-256.

23 Colbert AP, Larsen A, Chamberlin S, Decker C, Schiffke HC, Gregory WL, Thong T: A multichannel system for continuous measurements of skin resistance and capacitance at acupuncture points. J Acupunct Meridian Stud 2009;4:259-268.

24 Kramer S, Winterhalter K, Schober G, Becker U, Wiegele B, Kutz DF, Kolb FP, Zaps D, Lang PM, Irnich D: Characteristics of electrical skin resistance at acupuncture points in healthy humans. J Altern Complement Med 2009:4:1-6.

25 Ahn AC, Martinsen OG: Electrical characterization of acupuncture points: technical issues and challenges. J Altern Complement Med 2007;8:817824.

26 Aird M, Coyle M, Cobbin DM, Zaslawski C: A study of the comparative accuracy of two methods of locating acupuncture points. Acupunct Med 2000;1:15-21.

27 Coyle M, Aird M, Cobbin DM, Zaslawski C: The cun measurement system: an investigation into its suitability in current practice. Acupunct Med 2000; 1:10-14.

28 Xinnong C: Chinese Acupuncture and Moxibustion. Beijing, Foreign Languages Press, 1999.

29 Lian YL, Chen CY, Hammes M, Kolster BC: The Seirin Pictorial Atlas of Acupuncture - an Illustrated Manual of Acupuncture Points. Edited by Ogal HP, Stör W. Köln, Könemann, 2000, pp 42, 202.

30 Dincer F, Linde K: Sham interventions in randomized clinical trials of acupuncture - a review. Complement Ther Med 2003;4:235-242. 